\title{
Percutaneous endoscopic gastrostomy using \\ 10-cc syringe tubes for amyotrophic lateral sclerosis patients with limited mouth opening
}

Percutaneous endoscopic gastrostomy (PEG) is the most common method of delivering long-term enteral feeding to patients who are unable to take adequate nutrition by mouth [1]. We sometimes encounter patients for whom it is difficult to install the mouthpiece because of limitations of their mouth opening, such as in patients with neuromuscular disorders. In such cases we had tried transnasal insertion of the PEG, nasogastric feeding, or laparoscopic gastrostomy tube placement [2-4]. However, transoral insertion of PEG has many advantages over the other procedures [2-5]. For that reason, we tested the feasibility of using a 10-cc syringe instead of a conventional mouthpiece during PEG in patients with limited mouth opening.

A total of 12 cases ( 7 women, 5 men; mean age 63.5 years old) were enrolled from September 2010 to September 2011. All were patients with amyotrophic lateral sclerosis (ALS) and limited mouth opening. The 10-cc syringe was cut to a length of $4.5 \mathrm{~cm}$ with a compass saw, and the cut surface $(1.5 \mathrm{~cm}$ wide) was smoothed with sandpaper ( $\bullet$ Fig. 1). PEG was performed using a standard upper endoscope (GF-260; Olympus, Tokyo, Japan) and gastrostomy set (PEG-24PULL-S; Cook Medical, Bloomington, Indiana, USA).

The median procedure time was $10.66 \pm$ 3.64 minutes. The endoscope and PEG tube easily passed through the mouthpiece of the 10-cc syringe without any resistance. Also, the syringe could be inserted into the side of the mouth in patients with difficulty biting in the middle of the mouth ( Fig. 2). There were no difficulties in handling the endoscope during the procedures. No damage to the endoscope or PEG tube was noted in any of the cases. There were no PEG procedure-relat-

\section{Video 1}

Percutaneous endoscopic gastrostomy (PEG) using 10-cc syringe tubes for an amyotrophic lateral sclerosis (ALS) patient with limited mouth opening.
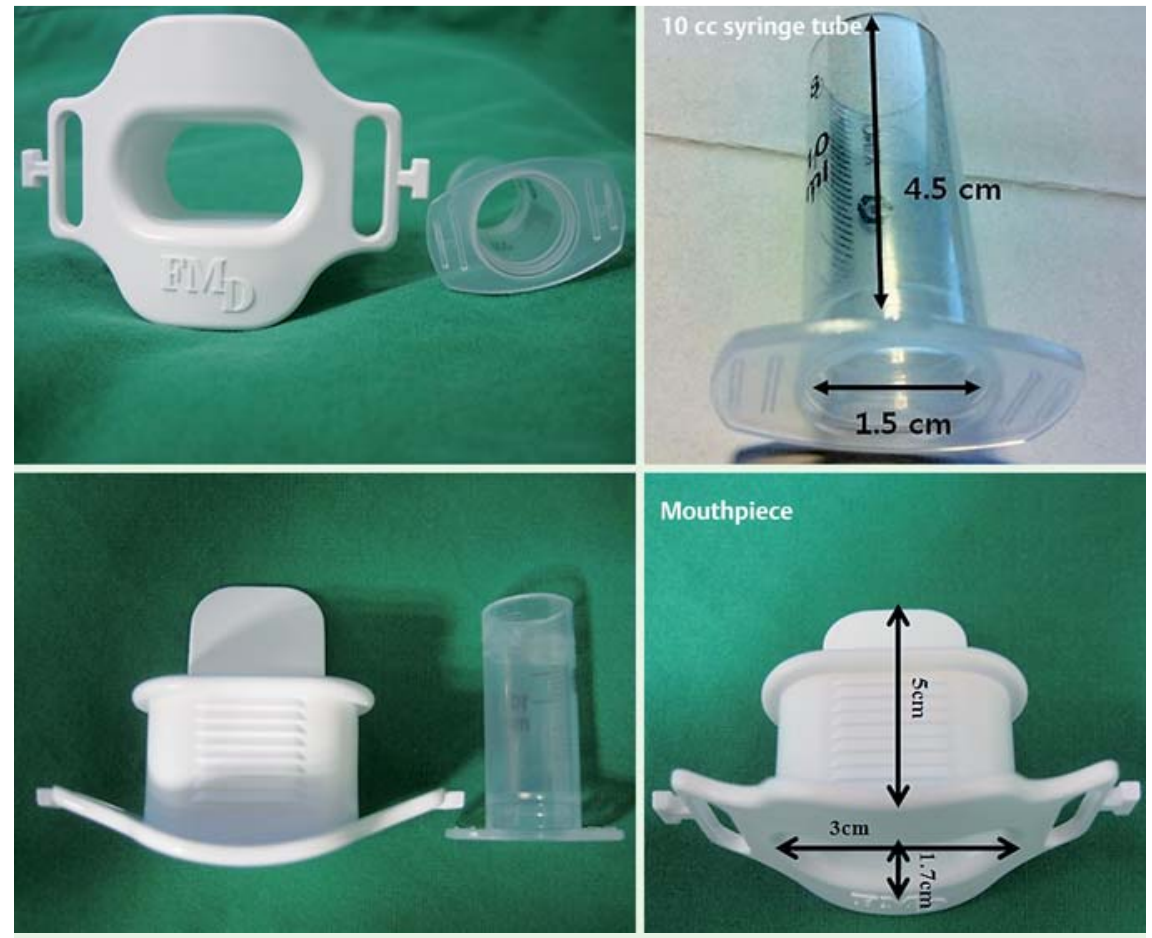

Fig. 1 10-cc syringe tube compared with conventional mouthpiece.
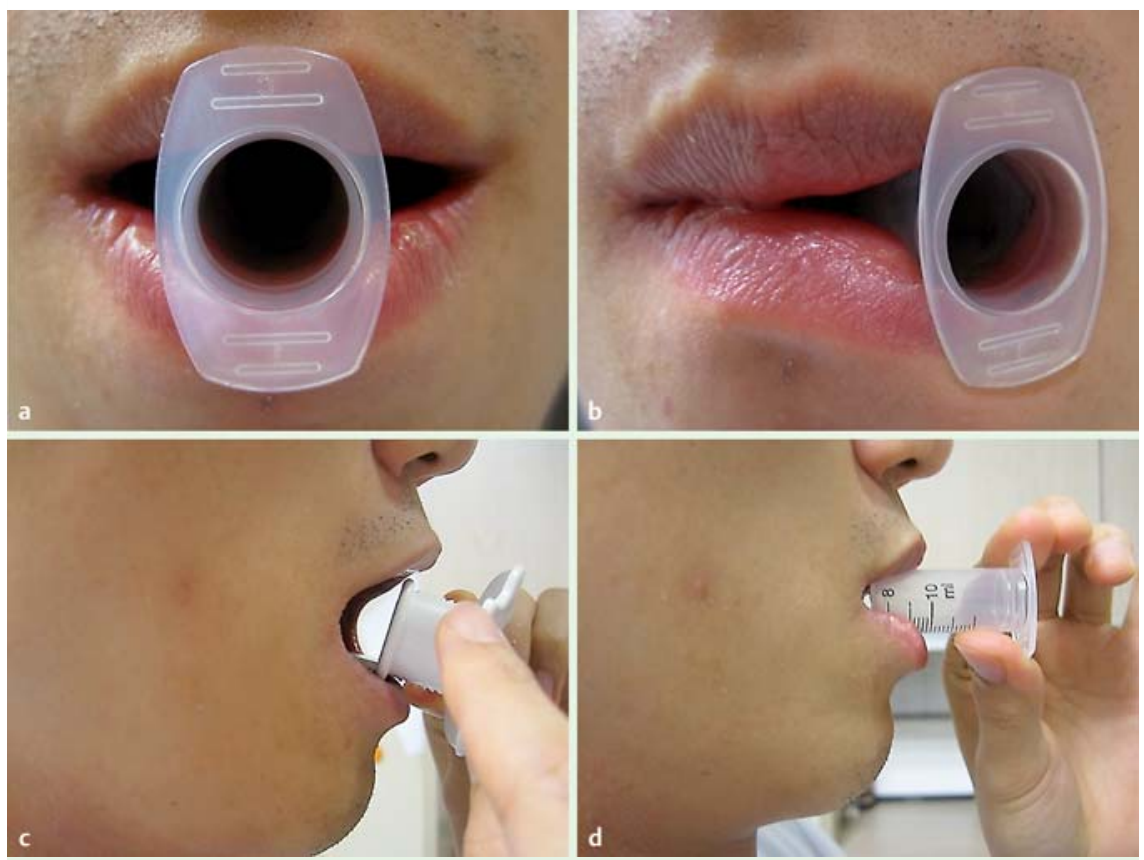

Fig. 2 A patient holding between his teeth: a, b, $\mathbf{d}$ a 10-cc syringe; $\mathbf{c}$ a conventional mouthpiece. The 10-cc syringe can more easily be inserted in a relatively small mouth opening than the conventional mouthpiece can be. The syringe can also be inserted into the side of mouth in cases with difficulty biting into the middle of the mouth. 
ed or 10-cc syringe-induced complications.

These results suggest that PEG using a 10 -cc syringe is a safe and effective method in ALS patients with limited mouth opening. However, more studies are needed to confirm this result.

Endoscopy_UCTN_Code_TTT_1AO_2AK

Competing interests: None

\section{S. P. Lee, H. L. Lee, D. C. Kim,}

K. N. Lee, O. Y. Lee, H. S. Choi, B. C. Yoon, D. W. Jun, J. S. Hahm, Y. W. Joo

Department of Internal Medicine, Hanyang University College of Medicine, Seoul,

Korea

\section{References}

1 Kurien M, McAlindon ME, Westaby $D$ et al. Percutaneous endoscopic gastrostomy (PEG) feeding. BMJ 2010; 340: c2414

2 Counihan T, Napolitano LM, Heard SO. Transnasal insertion of percutaneous endoscopic gastrostomy in a patient with intermaxillary fixation: case report. J Trauma 1996; 41: $530-532$

3 Dennis MS, Lewis SC, Warlow C. Effect of timing and method of enteral tube feeding for dysphagic stroke patients (FOOD): a multicentre randomised controlled trial. Lancet 2005; 365: $764-772$

4 Norton B, Homer-Ward M, Donnelly MT et al. A randomised prospective comparison of percutaneous endoscopic gastrostomy and nasogastric tube feeding after acute dysphagic stroke. BMJ 1996; 312: 13-16

5 Malmgren A, Hede GW, Karlstrom B et al. Indications for percutaneous endoscopic gastrostomy and survival in old adults. Food Nutr Res 2011; 55
Bibliography

DOI http://dx.doi.org/ 10.1055/s-0032-1306796 Endoscopy 2012; 44: E190-E191

(c) Georg Thieme Verlag KG Stuttgart · New York ISSN 0013-726X

Corresponding author H. L. Lee, MD, PhD

Department of Internal Medicine Hanyang University College of Medicine 17 Haengdang-dong

Seongdong-gu

Seoul 133-792

Korea

Fax: +82-2- 2298-9183

alwayshang@hanyang.ac.kr 